\title{
Desulfurization of Vulcanized Rubber Particles Using Biological and Couple Microwave-Chemical Methods
}

\author{
C. Valdés ${ }^{1}$, C. Hernández ${ }^{2}$, R. Morales-Vera ${ }^{2,3}$ and R. Andler ${ }^{2 *}$ \\ ${ }^{1}$ Centro de Investigación de Estudios Avanzados Del Maule (CIEAM), Vicerrectoría de Investigación y Postgrado, Universidad \\ Católica Del Maule, Talca, Chile, ${ }^{2}$ Centro de Biotecnología de Los Recursos Naturales (CENBIO), Escuela de Ingeniería en \\ Biotecnología, Universidad Católica Del Maule, Talca, Chile, ${ }^{3}$ Facultad de Ingeniería, Ciencias y Tecnología, Universidad Bernardo \\ O'Higgins, Santiago, Chile
}

\section{OPEN ACCESS}

Edited by:

Ravi Naidu,

University of Newcastle, Australia

Reviewed by:

Fabiula De Sousa,

Federal University of Pelotas, Brazil Gonzalo Martinez-Barrera, Universidad Autónoma del Estado de

México, Mexico

Mohd Mustafa Al Bakri Abdullah, Universiti Malaysia Perlis, Malaysia

${ }^{*}$ Correspondence:

R. Andler

randler@ucm.cl

Specialty section: This article was submitted to

Toxicology, Pollution and the Environment,

a section of the journal

Frontiers in Environmental Science

Received: 24 November 2020 Accepted: 02 July 2021 Published: 20 July 2021

Citation:

Valdés $C$, Hernández $C$, Morales-Vera $R$ and Andler $R$ (2021) Desulfurization of Vulcanized Rubber Particles Using Biological and Couple

Microwave-Chemical Methods.

Front. Environ. Sci. 9:633165.

doi: 10.3389/fenvs.2021.633165
Currently, recycling or degradation treatments for tires are an enormous challenge. Despite efforts to dispose of or recycle it, rubber waste is increasing year by year worldwide. To create a rubber-recycling system, several researchers have proposed tire desulfurization. In this study, we compare two methods: one biological, using Acidobacillus ferroxidans in shake $250 \mathrm{ml}$ flask experiments, and one chemical using, for the first time, microwaves and an aqueous solution. The results of these methods were analyzed through sulfate quantification, cross-linking differences, Fourier transform infrared spectroscopy (FTIR) and scanning electron microscopy with energy disperse spectroscopy (SEM-EDS). We observed that the amount of sulfates generated by the chemical system was 22.40 (mg/L)/ $\mathrm{g}$ of rubber, which was 22-times higher than the biological system, which generated 1.06 (mg/L)/g of rubber. Similarly, after cross-linking studies, a 36\% higher decrease after the chemical treatment was observed. When using FIIR analysis, the disappearance of characteristic bands corresponding to functional groups containing sulfur bonds and metal oxides were observed by treating the sample with both desulfurization methods. Morphological changes on the rubber surface structure was also demonstrated by SEMEDS analysis with the appearance of holes, cracks and changes in the porosity of the material. This work analyzed two different non-aggressive desulfurization approaches that might be used as methods for rubber recycling processes.

Keywords: Acidithiobacillus ferrooxidans, desulfurization, devulcanization, microwave treatment, rubber degradation, rubber recycling

\section{INTRODUCTION}

Millions of tires are discarded every year, representing up to $12 \%$ of the total accumulated solid waste. This type of waste increases annually by around 17 million tons. Recent studies project that, by 2030, about 1,200 million tons of tires will be discarded every year (Formela et al., 2019). Discarded tires generate problems as accumulation of mosquitos, and cause of unwanted fires generating toxic vapors (Stevenson et al., 2008). The main constituent of tires is rubber, which can be obtained from fossil sources (synthetic rubber) or from the tree Hevea brasiliensis (natural rubber) (Subramaniam, 1987). When analyzing the dry weight of natural rubber, it consists of $90 \%$ poly (cis-1,4-isoprene) and less than $10 \%$ of other constituents such as proteins, carbohydrates, lipids, resins, and inorganic salts (Nawong et al., 2018). For commercial purposes, rubber is subjected to a vulcanization process 
where the poly (cis-1,4-isoprene) chains are cross-linked between them by heat in the presence of sulphur (Berekaa et al., 2000). The process is based on adding a percentage of elemental sulfide to rubber, which is subsequently subjected to heat at $140^{\circ} \mathrm{C}$ and 4 atm of pressure. As a result, the original material, which is sticky and non-elastic, becomes a non-sticky and elastic material. Due to cross-linking, it is not possible to deform the material using heat, as it is done with thermoplastics such as polyolefins (polyethylene or polypropylene) (Holst et al., 1998). In addition, to improve abrasion resistance, carbon black is added to the rubber during vulcanization (Larsen et al., 2006). Carbon black together with silica are the second major components of a tire, after the polymer of rubber (Bockstal et al., 2019).

Since procedures such as tire burning, tire burying, and depositing tires on landfills are harmful, several methods and mechanisms for rubber degradation have been studied (Sienkiewicz et al., 2017; Mok and Eng, 2018). Rubber waste can be treated by chemical, mechanical and biological processes. However, as a result of the high degradation resistance of rubber materials, no clean and efficient processes have been established to date. One of the reasons that vulcanized rubber is difficult to degrade is due to the presence of disulfide bridges, which link the rubber molecules together in a strong bond (Bredberg et al., 2002). Consequently, a first desulfurization step is essential for improving the overall degradation process (Andler, 2020).

Biological desulfurization methods as rubber degradation of ground tires has been reported. (Li et al., 2011). The Fourier Transform Infrarred Spectroscopy (FTIR) and X-ray photoelectron spectroscopy (XPS) analysis has been demonstrated how Thiobacillus ferrooxidans was able to breakdown sulfur crosslinks. In another work using the same bacteria, the bioconversion from sulfide to sulfate was studied. After a 20 days cultivation, an $8 \%$ conversion was reached with changes in the physical properties of the material (Chritiansson et al., 1998).

Acidithiobacillus is a gram-negative bacterium of the chemolithotrophic type. It was initially cataloged in the genus Thiobacillus (Vishniac and Santer, 1957); however, due to its high acidity tolerance, it was reclassified in the genus Acidithiobacillus (Kelly and Wood, 2000). This genus is divided into two groups: sulfuroxidizing species and sulfur- and iron-oxidizing species. Acidithiobacillus ferrooxidans corresponds to the latter group (Wang et al., 2019). This bacterium stands out for being used in mining to promote the oxidation of iron and sulfur compounds. A group of genes involved in the oxidation of reduced inorganic sulfur compounds (RISCs) has been described in A. ferrooxidans. Two genes homologous to $\operatorname{doxDA}$ encode a protein with thiosulfate/quinone oxidoreductase activity (AFE0044; AFE0048), and another five genes encode sulfur thiosulfate transferase proteins (AFE2558, AFE2364, AFE1502, AFE0529, and AFE0151). To date, the role they play in sulfur oxidation is not yet clear (Valdes et al., 2008).

Chemical treatments are another alternative for rubber recycling purposes (Sun et al., 2017), after treating waste silicone rubber composite insulator with $\mathrm{H}_{2} \mathrm{O}_{2}$ combine with graphite in an acid medium, obtained a material with better mechanical and thermal properties (Sun et al., 2017). Sulfuric acid has been used to treat crumb rubber in combination with ultraviolet light, as a result, the rubber's stiffness increased (Alawais and West, 2019). Surface modification of halloysite nanotubes have been reported to interact with rubber nanocomposites, using the vulcanization accelerant N-cyclohexyl-2-benzothiazole sulfenamide, improving the mechanical properties of the material (Zhong et al., 2016). Chemical methods supplemented with mechanical treatments have shown positive changes of the rubber properties, 2,2'dibenzothiazoledisulfde (DM), in combination with mechanical treatment, increases the content of oxygenated groups on the surface, increasing the swelling degree of the material 1.5 times (Liu et al., 2020).

Green chemistry approaches as ultrasound and microwaves treatments have been reported for rubber treatment. Ultrasound treatments for rubber particles of $100-150 \mu \mathrm{m}$ were obtained with a devulcanized surface (Dobrotă and Dobrotă, 2018). The energy consumption was around 2.5 times lower than a conventional mill (Formela et al., 2019). The use of microwaves at low temperatures is also described as a devulcanization treatment. Microwave treatment allows oxidation and degradation of rubber as an environmentally friendly alternative. Even with conventional microwaves, appreciable structural rubber changes can be detected by a thermo-oxidation process (Scuracchio et al., 2007). Although there are methods to digest complex compounds such as rubber using microwaves, it requires a high amount of acids. Alternative methods using moderate amounts of acids are needed to fulfill the green chemistry requirements (Pinheiro et al., 2019).

Devulcanization of rubber using microwaves is one of the most promising procedures due to its efficiency and low environmental consequences. An important advantage when compared against to conventional methods is that the application of heat is homogeneous and does not depend on conduction and/or convection of heat. Studies have reported the importance of the exposure time of the samples to microwaves, affecting the cross-linking of rubber. The polymer itself, such as copolymers of isoprene-butadiene, natural rubber, and butylated rubber, are important during the desulfurization process (de Sousa et al., 2017). It has been reported that the use of microwaves can decrease the toxic volatiles released in the pyrolysis of the waste crumb rubber used to generate asphalt, being a pretreatment option for this material (Yang et al., 2020).

Consequently, an efficient and environmentally friendly method is needed for the devulcanization of rubber in order to provide alternatives for recycling or degrading rubber waste. In this study, we compared two processes for the desulfurization of rubber particles. A chemical method based on microwaves at low acid concentrations, and a biological method using the bacterium A. ferrooxidans in shake flask experiments.

\section{MATERIALS AND METHODS}

\section{Rubber Material}

Rubber particles were purchased from Trelleborg AB, Germany. For all the experiments performed, a particle size between 1-2 mm was used.

\section{Microwave Treatment}

An Ethos Easy microwave with an SK-15 rotor was used for the chemical desulfurization treatment. A total of $250 \mathrm{mg}$ of rubber 
particles were added to $10 \mathrm{ml}$ of $1 \% \mathrm{HNO}_{3}$. The temperature program was set at $180^{\circ} \mathrm{C}$ for $5 \mathrm{~min}$ and $200^{\circ} \mathrm{C}$ for $30 \mathrm{~min}$.

\section{Bacterial Strains and Cultivation Conditions}

The bacterial strain used in this study was A. ferrooxidans ATCC 23270. For culture maintenance, the strain was grown using the medium DSMZ 70, adjusting the initial $\mathrm{pH}$ to 2.0. For the desulfurization cultures, a modified $9 \mathrm{~K}$ medium was used supplemented with $1 \%$ of vulcanized rubber particles. The particles were previously washed using ethanol $70 \% \mathrm{v} / \mathrm{v}$ for $24 \mathrm{~h}$. The medium composition was: $\left(\mathrm{NH}_{4}\right)_{2} \mathrm{SO}_{4}, 3.00 \mathrm{~g}$; $\mathrm{K}_{2} \mathrm{HPO}_{4}, 0.50 \mathrm{~g} ; \mathrm{MgSO}_{4} \cdot 7 \mathrm{H}_{2} \mathrm{O}, 0.50 \mathrm{~g} ; \mathrm{KCl}, 0.10 \mathrm{~g} ; \mathrm{Ca}\left(\mathrm{NO}_{3}\right)_{2}$, $0.01 \mathrm{~g}$; and $\mathrm{FeSO}_{4} \cdot 7 \mathrm{H}_{2} \mathrm{O}, 3.30 \mathrm{~g}$. Two cultivation conditions were evaluated: 1) with $1 \% \mathrm{w} / \mathrm{w}$ rubber particles and 2) without rubber particles. The $\mathrm{pH}$ was initially adjusted to two using $4 \mathrm{M} \mathrm{HCl}$ and monitored during the cultivations. Cultures were performed in $250 \mathrm{ml}$ shake flasks at $30^{\circ} \mathrm{C}, 150 \mathrm{rpm}$ for 4 weeks. Cell growth was measured by total cell count using a Neubauer chamber. Samples were analyzed every 7 days.

\section{Sulfate Ion Quantification}

The sulfate ion content was measured at the beginning and at the end of the cultivation e for all the biological assays and the microwave treatment. Consequently, $5 \mathrm{ml}$ of supernatant (for the biological treatment) and $5 \mathrm{ml}$ of the $1 \% \mathrm{HNO}_{3}$ solution (for the chemical treatment) were mixed with $100 \mu \mathrm{L}$ of a barium chloride solution $\left(\mathrm{Ba}_{2} \mathrm{Cl}, 20 \mathrm{~g}\right.$; acetic acid $10 \mathrm{~N}, 75 \mathrm{ml}$; glycerol $25 \% \mathrm{v} / \mathrm{v}$, $25 \mathrm{ml}$ ). The mixture was mixed vigorously, and the absorbance was measured using a spectrophotometer at $420 \mathrm{~nm}$. Sodium sulfate was used as standard in a range of $0.02-1.00 \mathrm{mg} / \mu \mathrm{L}^{-1}$. Sulfate quantification data was analyzed by ANOVA using the software SPSS10. The multiple comparison test Tukey was performed for significant differences of the treatments. Sulfate analysis was performed in duplicates.

\section{Cross-Link Density Determination}

To determine the cross-link density, the method described by Mok and Eng (2018) was performed using toluene as the organic solvent. Rubber particles $(0.5 \mathrm{~g})$ were mixed with $1 \mathrm{ml}$ of toluene and incubated for 5 days in the dark using a fume hood. After this period, the solvent was discarded, and the mass was determined $\left(\mathrm{m}_{3}\right)$. The mass of the dry polymer $\left(\mathrm{m}_{1}\right)$ was obtained by heating the particles at $70^{\circ} \mathrm{C}$ for $72 \mathrm{~h}$. The mass of the solvent in the swollen sample $\left(\mathrm{m}_{2}\right)$ was calculated as follows:

$$
m_{2}=m_{3}-m_{1}
$$

The volume fraction of the rubber in its swollen state $(\mathrm{Vr})$ was calculated as follows:

$$
V_{r}=\frac{\left(m_{1} / \rho_{1}\right)}{\left(m_{1} / \rho_{1}\right)+\left(m_{2} / \rho_{2}\right)}
$$

where $V_{r}$ is the volume fraction of the rubber in its swollen state, and $\rho_{1}$ and $\rho_{2}$ are the density of the dry polymer sample and the density of the solvent $\left(\mathrm{mol} / \mathrm{cm}^{3}\right)$, respectively.

The cross-link density ( $v$ ) was calculated as follows (Liu et al., 2020):

$$
\nu=\frac{-1}{2 v_{s}} \frac{\ln \left(1-V_{r}\right)+V_{r}+\chi V_{r}^{2}}{V_{r}^{1 / 3}-V_{r} / 2}
$$

where $v$ is the cross-link density mole per unit of volume (mol/ $\mathrm{cm}^{3}$ ) and $\chi$ is the Flory-Huggins polymer-solvent interaction parameter ( 0.35 for the rubber-toluene mixture; (Dzulkifli et al., 2016).

\section{Fourier Transform Infrared Spectroscopy Analysis}

The rubber particles were separated from the reaction medium by filtration using a glass filter with a porosity of 3 (nominal pore size: $16-40 \mathrm{~mm}$ ). A $10 \mathrm{mg}$ of dried rubber particles were analyzed by attenuated total reflectance (ATR)-FTIR. The infrared spectra were obtained using a FTIR spectrometer (Agilent, Cary 630) with the ATR technique. Absorbance was measured in the wavelength range of $400-4,000 \mathrm{~cm}^{-1}$, whereas the resolution was $4 \mathrm{~cm}^{-1}$. For each sample, 64 scans were performed, and the background was subtracted using Agilent MicroLab PC software.

\section{Scanning Electron Microscopy/Elemental Analysis by Energy Dispersive}

The method was based on ASTM E1508 standard " Standard Guide for Quantitative Analysis by Energy-Dispersive Spectroscopy". The microscope used was TESCAN VEGA 3 with probe EDS BRUKER QUANTAX, samples were covered by a cathodic spray system with Palladium Gold in Hummer 6.2 equipment.

\section{RESULTS}

\section{Growth of Acidithiobacillus ferrooxidans in Shake Flasks}

The $A$. ferrooxidans cultures were kept under constant agitation with a controlled temperature for 4 weeks, while cell growth and $\mathrm{pH}$ was monitored every 7 days. Figure 1 shows the bacterial growth of $A$. ferrooxidans and the $\mathrm{pH}$ evolution over time. It was possible to observe that cell growth was enhanced with the presence of rubber particles, showing maximum growth over 3 weeks, while culture without rubber in the medium showed lower growth, reaching $3.4 \times 10^{6}$ cells $/ \mathrm{mL}$. Rubber treatment with T. ferrooxidans has been reported for the desulfurization of tire rubber, where a similar culture medium (modified Silverman medium) was used for a 30 days incubation period ( $\mathrm{Li}$ et al., 2011). In that experiment, cell growth was negatively affected when rubber was added to the medium (after $24 \mathrm{~h}$ ). This difference could be attributed to the fact that rubber was not treated with ethanol for partial elimination of residues present in the rubber that might prevent the growth of the bacteria. However, a similar cell density was reached in both studies ( $\mathrm{Li}$ et al., 2011). Rubber treatments using $9 \mathrm{~K}$ culture medium have been previously reported under similar conditions, where the oxidative capacity of iron T. ferrooxidans was also measured. 


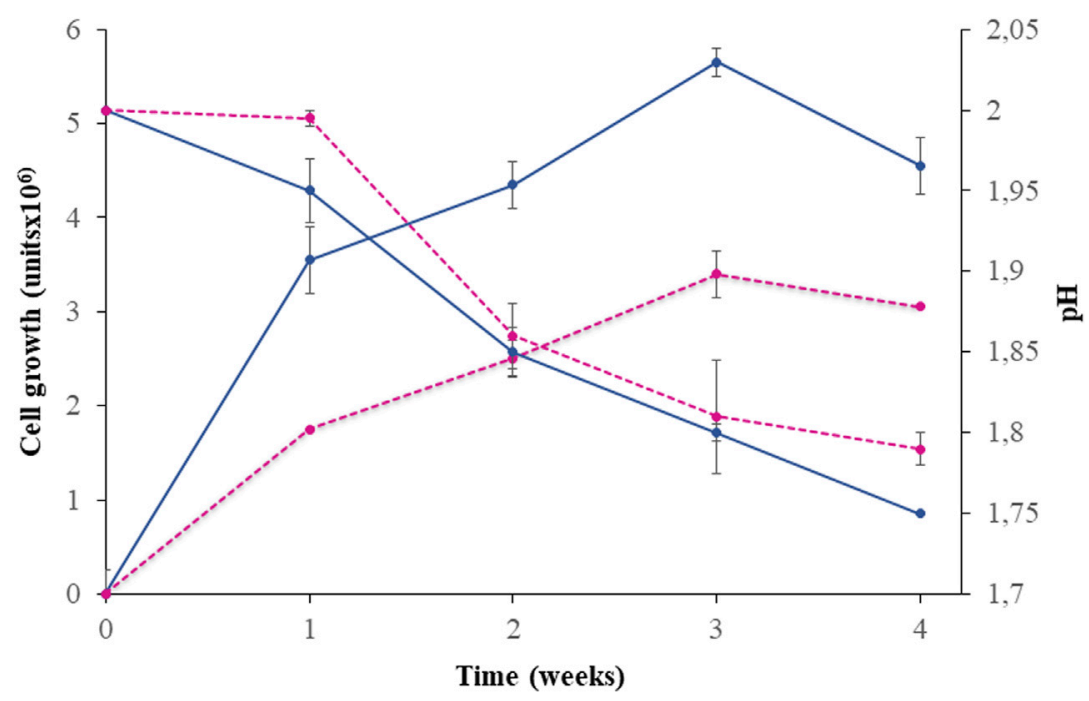

FIGURE 1 | Growth of $A$. ferrooxidans (A) and pH variation (B) in shake flasks over 4 weeks. The cultivation medium was the modified $9 \mathrm{~K}$ medium supplemented with $1 \% \mathrm{w} / \mathrm{w}$ rubber particles (solid line), and without rubber particles (dashed line). Measurements were done in duplicates and the standard error is presented in the figure.

TABLE 1 | Quantification of sulfate ion and determination of cross-link densities after biological and chemical treatments for Gram of rubber. For the biological negative control, the cultivation medium did not include rubber particles. For the chemical negative control, rubber particles were suspended in $1 \% \mathrm{HNO}_{3}$ without the microwave treatment. ND: not detected. Statistical analysis showed significant differences between all the different treatments. Standard error is showed for sulfate quantification.

Treatment

Biological

Biological control

Chemical

Chemical control
Sulfate $(\mathrm{mg} / \mathrm{L}) / \mathrm{g}$ of rubber

$$
\begin{gathered}
1.06 \pm 0.16 \\
0.20 \pm 0.06 \\
22.40 \pm 0.19
\end{gathered}
$$

ND
Cross-link densities $\left(\mathrm{mol} / \mathrm{cm}^{3}\right) / \mathrm{g}$ of rubber

$$
\begin{gathered}
13 \times 10^{3} \\
20.4 \times 10^{3} \\
8.0 \times 10^{3} \\
20.4 \times 10^{3}
\end{gathered}
$$

(Jiang et al., 2010). In the present study, it was possible to detect a decrease in the $\mathrm{pH}$ in all treatments after the first week, reaching a final $\mathrm{pH}$ between 1.7 and 1.8. which do not interfere with $T$. ferrooxidans growth, as it is mentioned in previous studies (Valdes et al., 2008).

The culture was then subjected to analysis as sulfate quantification and rubber surface analysis by FTIR and SEM-EDS.

\section{Sulfate Ion Quantification}

Sulfates were quantified in order to evaluate the desulfurizing capacity of A. ferrooxindans and the microwave treatment. As shown in Table 1, cultures containing rubber particles and iron reached a sulfur concentration of $1.06 \pm 0.16(\mathrm{mg} / \mathrm{L}) / \mathrm{g}$ of rubber after 30 days of cultivation. An increment of sulfate was observed when rubber was present in the cultivation medium over sulfate concentration reached in the absence of rubber $(0.10 \pm 0.03 \mathrm{~g} / \mathrm{L})$. A sulfate concentration of $0.17 \mathrm{~g} / \mathrm{L}$ was reported by $\mathrm{Li}$ et al. ( $\mathrm{Li}$ et al., 2011) in cultures of $A$. ferrooxidans after 14 days. In another report using the same microorganism, $0.18 \mathrm{~g} / \mathrm{L}$ of sulfate ion was obtained after 20 days of cultivation (Jiang et al., 2010).
Desulfurization in latex gloves has been reported with $A$. ferroxidans with a release of sulphate up to $8 \% \mathrm{w} / \mathrm{w}$ over 20 days; this result is more efficient when comparing with Thiobacillus thioparus and Acidianus brierleyi, under the same treatment conditions (Chritiansson et al., 1998). It is known that A. ferrooxidans can couple sulfur oxidation with electron transfer with a high redox potential for $\mathrm{CO}_{2}$ fixation, releasing sulfate ions at the end of the oxidation process (Zhan et al., 2019).

For a proper comparison, the same initial concentration of rubber particles was tested in both processes. When analyzing the sulfate concentration after the chemical desulfurization with a microwave, $5.6 \mathrm{~g} / \mathrm{L}$ was obtained; this is about 10 times higher than the biological treatment. No investigations were found regarding sulfate quantification by microwaves with the present technique. It is relevant to mention that the use of acids is reported as a medium of desulfurization; for example, sulfuric acid has been used for the desulfurization of fuels such as diesel and kerosene in the absence of catalysts (Shakirullah et al., 2010). Sulfur carbon desulfurization has also been reported in the presence of acids, and can also remove minerals (Mukherjee and Borthakur, 2001). Our results show the feasibility of optimizing 


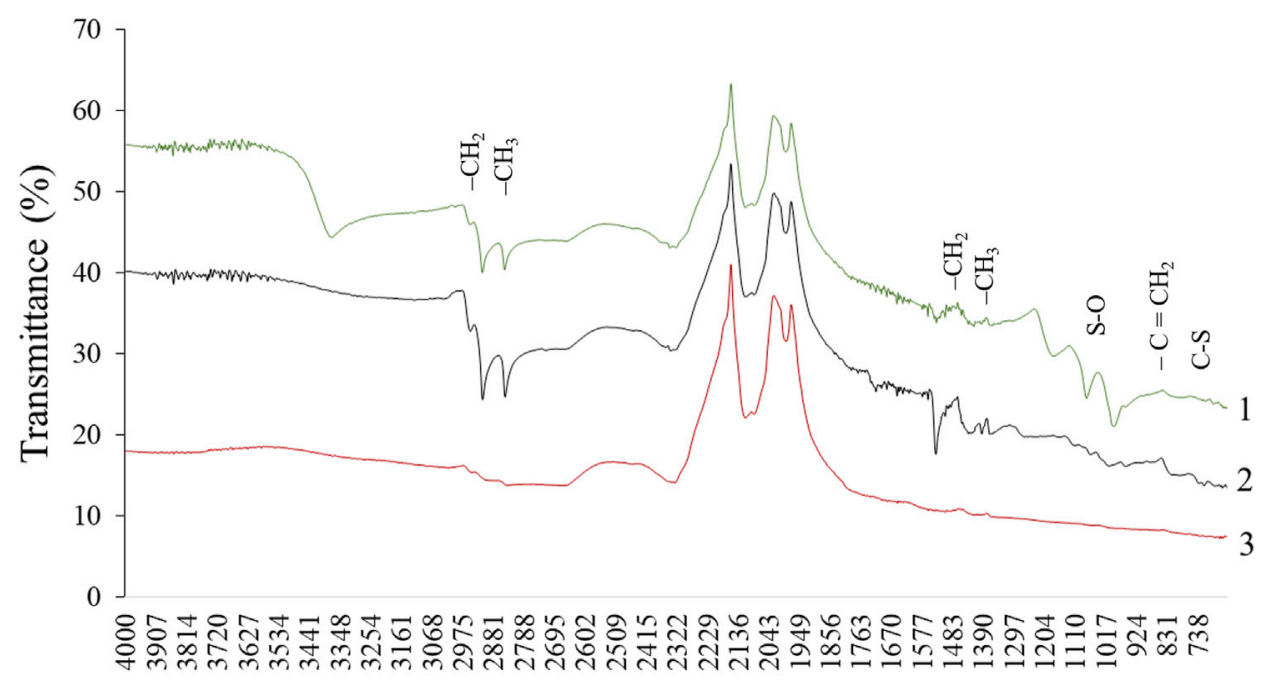

Wavelength $\left(\mathrm{cm}^{-1}\right)$

FIGURE 2 | FTIR spectra of rubber particles after biological treatment (A), after chemical treatment (C), and without treatment as a negative control (B).

the best balance between desulfurization and the concentration of acid to be used.

\section{Cross-Link Density}

The Flory-Rehner equation was employed to determine the cross-link density for the rubber particles after both the biological and the microwave treatment (Table 1). It was possible to observe differences in the cross-linking between the treated and untreated rubber particles as well as differences between the biological and chemical methods. Using the microwave method, a greater decrease in crosslinking was observed. From the untreated rubber (control), the cross-link density of the samples after the biological treatment decreased $36 \%$, reaching a value of $13\left(\mathrm{~mol} / \mathrm{cm}^{3}\right) /$ $\mathrm{g}$ of rubber, while a decrease of $60 \%$ was obtained after the chemical treatment with the microwave, reaching a value of $8.0 \times 10^{-3}\left(\mathrm{~mol} / \mathrm{cm}^{3}\right) / \mathrm{g}$ of rubber. In previous biological treatments of rubber where the cross-link density was studied, values of $5.8 \times 10^{-5} \mathrm{~mol} / \mathrm{cm}^{3}$ were reported (Jiang et al., 2010). Depending on the rubber content filling (phr), different cross-link densities can be obtained between $8.0 \times$ $10^{-4}$ and $1.3 \times 10^{-3} \mathrm{~mol} / \mathrm{cm}^{3}$ (Li et al., 2011).

\section{Rubber Particle Analysis by Fourier Transform Infrared Spectroscopy}

In order to evaluate structural variations at the surface of the particles after the desulfurization treatments. Rubber particles were recovered, dried, and analyzed using FTIR (Figure 2). It was possible to detect a variation in the polymer structure after the biological and chemical treatments corresponding to groups $\left(-\mathrm{C}=\mathrm{CH}_{2}\right.$ ) at a wavelength of $874 \mathrm{~cm}^{-1}$ (Colom et al., 2016). This chemical structure is characteristic of the isoprene repetitive unit in tire rubber. The band at $1,360 \mathrm{~cm}^{-1}$ was also modified in both desulfurization approaches, which is related to $\left(-\mathrm{CH}_{3}\right)$ groups of the rubber structure (de Sousa et al., 2017). When analyzing peaks at 750 and $1,083 \mathrm{~cm}^{-1}$, relating to C-S and S-O bonds respectively (de Sousa et al., 2017), strong variations were found. A clear modification of the group was shown after the biological treatment due to superficial exposure of the functional groups. On the other hand, those groups were lost after the microwave treatment, showing stronger variations and a release of the $\mathrm{C}-\mathrm{S}$ and $\mathrm{S}-\mathrm{O}$ groups from the rubber particle surface. A band close to $1,452 \mathrm{~cm}^{-1}$ corresponding to methylene, part of the isoprene structure (Colom et al., 2016), was observed in the control sample, and no visible in the spectra corresponding to the microwave treatment. The band close to $1,021 \mathrm{~cm}^{-1}$ was associated with rubber carbon black (Colom et al., 2016). This band was altered after the biological treatment and was not observe after the microwave treatment. The peaks $2,924 \mathrm{~cm}^{-1}$ and $2,854 \mathrm{~cm}^{-1}$ are attributable to $\mathrm{CH}_{2}$ and $\mathrm{CH}_{3}$ streching respectively, detected in artificial and natural rubber (Gorassini et al., 2016).

\section{Rubber Particle Analysis by Scanning Electron Microscopy/Elemental Analysis by Energy Dispersive}

SEM photographs show that the surface suffered small fractures after treating the rubber with both biological and chemical desulfurization methods (Figure 3). However, at 500x an increase in surface pores by the chemical treatment was observed, accounting for the greater wear of the surface product of the severity of the treatment. EDS analysis shows a decrease in $\mathrm{O}$ and $\mathrm{S}$ content at the rubber surface after treatments, increasing the observable $\mathrm{C}$ versus the control. The chemical 


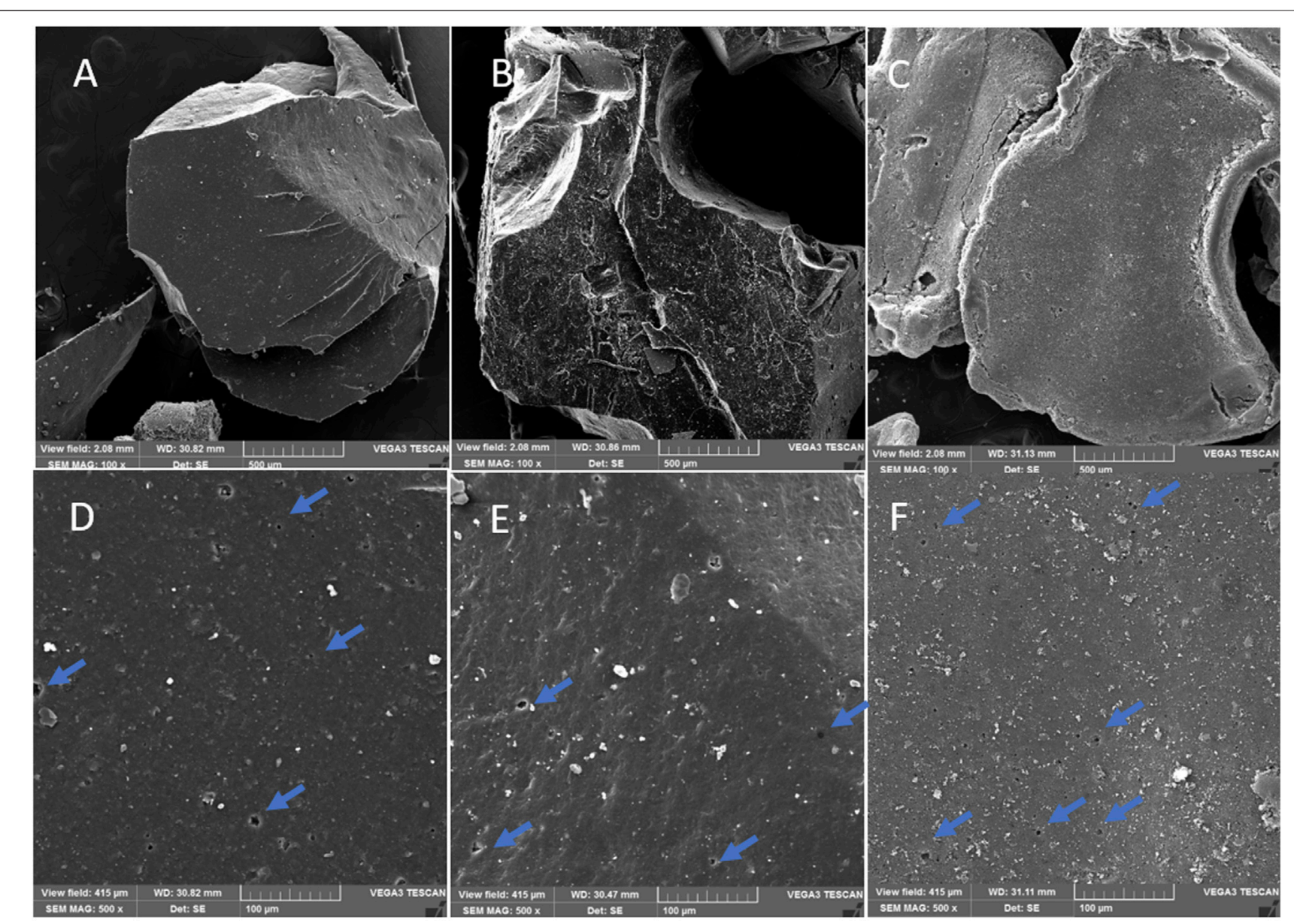

FIGURE 3 | Particle morphology and observable porosity in the analyzed samples, corresponding to control at 100x (A) and 500x (D), biological treatment at 100x (B) and 500x (E), and chemical treatment at 100x (C) and 500x (F). Blue arrows show pores on the surface.

treatment shows a Si content 10-times higher than the control, indicating the oxidation of the rubber surface, exposing the Si of the innermost layers. No relevant modification is appreciated by the biological treatment. Other elements such as $\mathrm{Al}, \mathrm{K}$, and $\mathrm{Mg}$ were detected with less than $0.01 \%$.

\section{DISCUSSION}

\section{Biochemistry of Biological and Chemical Desulfurization Processes}

The sulfur-uptake mechanism in $A$. ferrooxidans is not completely clear and some key enzymes have still not been identified. A sulfur dioxygenase (SDO) has been reported in Acidithiobacillus, the first enzyme reported for elemental oxidation of extracellular sulfur. SDO activity has also been detected in mitochondria, animals, and heterotrophic bacteria, where persulfide dioxygenase (ETHE1) and persulfide dioxygenase (PDO) are proposed as homologs of SDO in mitochondria and heterotrophic bacteria, respectively (Kabil and Banerjee, 2012; Sattler et al., 2015). Sulfur oxygenase reductase (SOR) is also found in Acidithiobacillus, which can generate molecules such as thiosulfate, sulfite, and sulfide (Ghosh and Dam, 2009). The tetrathionate hydrolase (ThetH) protein has been reported in A. ferroxidans (Sugio et al., 2009). This enzyme can also generate thiosulfate, sulphite, and sulfur from reduced sulfur species; however, ThetH's mechanism is still unclear (Tano et al., 1996; Beard et al., 2011). Knockout studies of this gene have been done in A. Ferroxidans, demonstrating the need for the ThetH to oxidize sulfur compounds present in selective media (Yu et al., 2014). However, it has been reported that this protein could be present extracellularly (Beard et al., 2011), which suggests that this is one of the enzymes that degrades the solid rubber present outside the bacterium when treatment systems in bioreactors by heterogeneous catalysis are used.

From a biochemical point of view, treatment using microorganisms allows the action of enzymes which causes the desulfurization of the material. The ability of microorganisms to desulfurize dibenzothiophene (a sulfur compound from petroleum) through the sulfoxide-sulfone-sulfinate-sulfate (4S) 
pathway has been proposed, where sulfate can also be consumed as an assimilation pathway by microorganisms (Soleimani et al., 2007). It has been reported in other genera of bacteria that the desulfurization performance of the dszA and dszC enzymes during the desulfurization of dibenzothiophene does not increase in the presence of metals such as $\mathrm{Fe}^{+2}, \mathrm{Fe}^{+3}$, and $\mathrm{Cu}^{+}$, and no decrease in activity was detected in the presence of Ethylenediaminetetraacetic acid (EDTA), suggesting that they do not depend on metallic cofactors (Ohshiro et al., 1997). Therefore, it is proposed that the presence of such enzymes would have a similar effect on the cross-linking of vulcanized rubber.

Regarding the microwave treatment, when rubber is subjected to temperatures of $200^{\circ} \mathrm{C}$ or more, devulcanization and shortening of the polymers is generated by rearrangement of the disulfide cross-links and the breakage of carbon-carbon bonds. The cross-links can be lost in volatile compounds in the shape of hydrogen sulfide $\left(\mathrm{H}_{2} \mathrm{~S}\right)$, carbon disulfide $\left(\mathrm{CS}_{2}\right)$, and sulfur dioxide $\left(\mathrm{SO}_{2}\right)$ (Asaro et al., 2018). This also shows that, in our microwave desulfurization tests, not all sulfur residues removed from the rubber structure would be present in the solution in forms such as sulfones, sulfates, or mercaptans.

During the microwave treatment, microwave energy is converted into thermal energy after being absorbed by the material. The polar molecules of a medium with dielectric characteristics move in the electric's direction field where thermal movement interferes with other molecules and the obstruction of intermolecular interactions generates internal friction. This converts the energy absorbed from the electrical field into thermal energy, increasing the temperature of the system (Tao et al., 2014). The thermal effects of microwaves can be associated with the ability to convert electromagnetic energy into thermal energy at a particular temperature and frequency; this capacity can be measured with the tangent of loss of the material $(\tan \delta)$ (Didier et al., 2006), where $\varepsilon$ " is the dielectric of material loss (which indicates the efficiency of the conversion of electrical energy into thermal energy) and $\varepsilon^{\prime}$ is the dielectric constant that indicates the polarization capacity (Ma et al., 2011).

Regarding the use of microwaves for treating rubber, temperature is a key factor, since it has been shown that oxidation can be generated by heat treatment of rubber and additives such as carbon black. Carbon black is an excellent microwave absorber (Ganchev et al., 1994; Formela et al., 2019) inducing the heat of non-polar compounds such as isoprene. Despite, the effect of conventional microwaves on the devulcanization of rubber, in the absence of solvents, has been reported, an advantage of using acids in the treatment of rubber is the possibility of releasing toxic compounds such as metals (Shakya et al., 2006). A. ferrooxidans decreases its catalytic activity as an iron oxidant in the presence of metals such as zinc (Cho et al., 2008), which is a common component in rubber, used as an activator of the vulcanization process (Adachi and Tainosho, 2004). The amount of nitric acid used in this study is low, so the contaminating effect of this solvent is not significant compared to conventional
TABLE 2 | Elemental distribution of $\mathrm{C}, \mathrm{O}$ and $\mathrm{S}$ on rubber particles after biological and chemical desulfurization treatments.

\begin{tabular}{lcccc}
\hline Treatment & $\mathbf{C ~ ( \% )}$ & $\mathbf{0}(\%)$ & S (\%) & Si (\%) \\
\hline Biological & 85.6 & 13.1 & 0.4 & 0.05 \\
Chemical & 91.1 & 6.9 & 0.1 & 0.38 \\
Control & 80.6 & 16.1 & 1.5 & 0.03 \\
\hline
\end{tabular}

rubber digestion (for elemental analysis) where pure acid is used (Monadjemi et al., 2016). Therefore, dilute nitric acid for microwave usage, it seems promising treatment for rubber desulfurization. The desulfurization capacity of materials such as coal in an acidic medium and in the presence of microwaves has also been reported. Up to $97 \%$ of inorganic sulfur can be removed by acid washing in combination with microwaves. In the presence of microwaves, the binding energy of C-S is weakened, facilitating its breakdown in the presence of acids; this result has been verified by FTIR analysis (Tao et al., 2014). It is noteworthy to mention that a low acid concentration (1\%) is used in the proposed chemical method, versus other described methods for treating rubber, which use high acid concentrations such as $\mathrm{H}_{2} \mathrm{SO}_{4}(95 \%)$. In addition, treatment with concentrated acid may require subsequent neutralization with base, which must also be in high concentrations (Cepeda-Jiménez et al., 2000; Alawais and West, 2019).

\section{Analysis of Rubber Particles After Biological and Microwave Treatments}

For the first time, the use of an aqueous phase during a microwave treatment is reported. Previously, authors have studied the effect on cross-linking using dried rubber and the microwave technique. Their results pointed out that cross-link densities after treatments were between $6.0 \times 10^{-5}$ and $12.0 \times 10^{-5} \mathrm{~mol} /$ $\mathrm{cm}^{3}$, using temperatures of $72,115,146,160,200$, and $220^{\circ} \mathrm{C}$ (de Sousa et al., 2017). Considering that the dissociation energy of the monosulfidic, disulfidic, and polysulfidic cross-links is between 268 and $285 \mathrm{~kJ} / \mathrm{mol}$; is less than the dissociation energy of a C-C bond with $351 \mathrm{~kJ} / \mathrm{mol}$ (Formela et al., 2019). Rubber desulfurization by microwave advantages adjusting parameters such as power, temperature, and incubation time, is the energy consumption, since is less energy intense than other reported treatments (Moseley and Woodman, 2009; Grewal et al., 2013).

The presence of new bands in FTIR analysis after the biological treatment indicate surface transformations possibly associated with rubber-decomposition processes. It can be seen that the chemical treatment with the microwave was more effective since the low concentration of nitric acid that was used increased the porosity of the material, facilitating the diffusion of thermal energy to break down sulfur bonds and other components that are part of the rubber surface. Tao et al. (2014) using FTIR method, observed the loss of sulfur bonds after a desulfurization treatment in an acidic and microwave medium. In the present study, the treatment of rubber using microwaves, bands corresponding to the $\mathrm{CH}_{2}$ groups $\left(1,475-1,450 \mathrm{~cm}^{-1}\right)$ and 


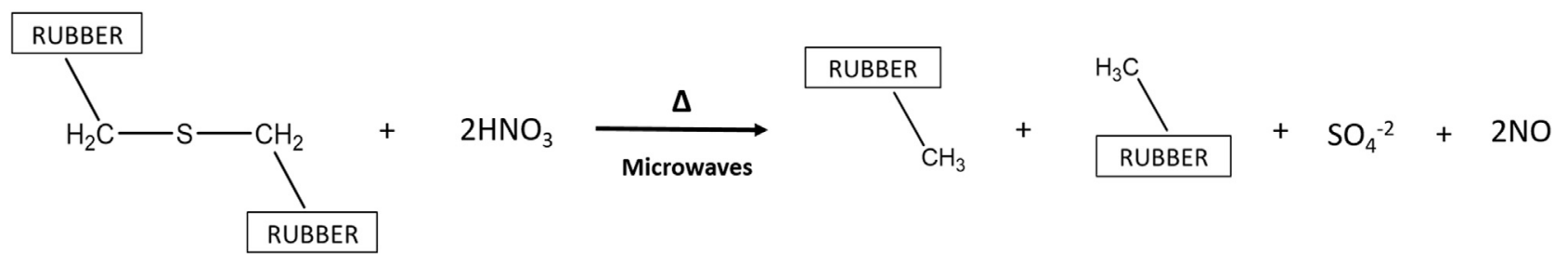

FIGURE 4 | Proposed mechanism for rubber desulfurization using $\mathrm{HNO}_{3}$ and microwaves.

bands corresponding to the $\mathrm{CH}_{3}$ group $\left(1,390-1,372 \mathrm{~cm}^{-1}\right)$ are lost. This is a reliable indicator of the effectiveness of the microwave in combination with acid since, in the absence of acid, the persistence of these functional groups has been reported for microwave treatments (de Sousa et al., 2017). Moreover, losing bands near $1,096 \mathrm{~cm}^{-1}$ and $1,540 \mathrm{~cm}^{-1}$, corresponding to $\mathrm{ZnO}$ and $\mathrm{SiO}_{2}$ (Colom et al., 2016), respectively, demonstrates the capacity of this system to remove the metal oxide in the structure of the treated rubber. Analysis of the desulfurization processes by FTIR is not only useful for analyzing materials such as rubber: this technique has also been reported for monitoring different desulfurization processes as acid treatments in fuels such as kerosene, where the loss of functional groups of molecules such as mercaptans has been observed (Tao et al., 2014; Colom et al., 2016).

The SEM analysis has been used to demonstrate the changes in the rubber surface against mechanical, chemical or biological treatments (Li et al., 2012; Aboelkheir et al., 2019). In this study, SEM analysis reveal morphological changes of the analyzed rubber surface after biological and chemical treatments in comparison with the control. Both treatments methods used, show a particle size of approximately $500-1,000 \mu \mathrm{m}$, so the particle size is not influenced by the treatments carried out compared to a reported work (Li et al., 2012). The size reported in this work is compatible for the treatments of our study, facilitating its implementation in systems with lowerperformance grinding. Samples observed at 500x show an increase in porosity after the chemical treatment of rubber, which is not observed in the rubber particle after the biological treatment. This result is also related to EDS analysis of $\mathrm{C}, \mathrm{O}, \mathrm{S}$, and $\mathrm{Si}$ in the surface (Table 2), where the carbon and silicium content increases in the rubber particles subjected to the treatments, especially after the application of the chemical treatment. The opposite occurs with $\mathrm{O}$ and $\mathrm{S}$, due to the fact of the increase of sulfates detected in the reaction mediums, probably as a result of a detachment from the rubber surface in addition to assimilation processes of these elements in the case of the biological treatment. Sulfur oxidation in A. ferrooxidans is a complex process that includes several enzymatic reactions, and some are still unknown (Zhan et al., 2019). It is proposed that there are oxidative mechanisms that allow the release of sulfur, transforming it to $\mathrm{SO}_{2}$. When sulfur is used as a substrate in aerobic cultures of $A$. ferrooxidans, the oxidation of reducing inorganic sulfur is carried out by a sulfur dioxygenase (Zhang et al., 2016) and sulfite is formed. Sulfites is a necessary intermediate during the oxidation of reduced sulfur, which can be further oxidized by two different mechanisms (Hirose et al., 1991). One is the direct oxidation by the action of sulfite cytochrome $c$ oxidoreductase and the other is an indirect oxidation to sulfate considering three sequential steps as indicated in the following equations (Zhan et al., 2019):

$$
\begin{gathered}
2 \mathrm{SO}_{2}^{-3}+2 \mathrm{AMP} \rightarrow 2 \mathrm{APS}+4 \mathrm{e}^{-} \\
(\text {APS reductase })(\text { Adenylyl-sulfate reductase }) \\
2 \mathrm{APS}+2 \mathrm{Pi}(2) \rightarrow 2 \mathrm{ADP}+2 \mathrm{SO} 2-4(\text { ADP sulfurylase }) \\
2 \mathrm{ADP} \rightarrow \mathrm{AMP}+\mathrm{ATP}(\text { adenylate kinase })
\end{gathered}
$$

The mechanism of desulfurization by microwaves in the presence of $\mathrm{HNO}_{3}$ has not been reported, it is proposed that $\mathrm{HNO}_{3}$ oxidize and remove $\mathrm{S}$ from rubber, obtaining $\mathrm{SO}_{4}$ and $\mathrm{NO}$ as a product (Figure 4).

\section{CONCLUSION}

Rubber desulfurization was achieved through a biological process by the bacteria $A$. ferrooxidans, and a chemical process using microwaves with low nitric acid concentration. From the performed experiments it can be established that the chemical/microwave treatment was more effective than the biological treatment. This was corroborated when comparing the results regarding sulfate measurement $(22.40 \mathrm{vs} 1.06(\mathrm{mg} /$ $\mathrm{L}) / \mathrm{g}$ of rubber), cross-link density $\left(4.0 \times 10^{3} \mathrm{vs} 6.5 \times 10^{3}(\mathrm{~mol} /\right.$ $\left.\mathrm{cm}^{3}\right) / \mathrm{g}$ of rubber) for biological and chemical/microwave treatments respectively. Additionally, FTIR analysis showed clear rubber surface modification in terms of the available functional groups when both of the treatments were performed. Regarding the use of microwaves, it is worth noting the low amount of nitric acid (1\%) used to promote strong structural changes in the rubber's surface, this is complemented by the SEM/EDS analysis that shows an increase in surface porosity and modification of the distribution of the $\mathrm{C}, \mathrm{O}, \mathrm{S}$, and $\mathrm{Si}$ elements of the rubber. Finally, both biological and chemical methods could be used as industrial desulfurization processes. Combining these methods might potentially increase the rubber devulcanization result, which is needed for rubber recycling. 


\section{DATA AVAILABILITY STATEMENT}

The original contributions presented in the study are included in the article/Supplementary Material, further inquiries can be directed to the corresponding author.

\section{AUTHOR CONTRIBUTIONS}

CV conducted the experiments, analyzed the data and drafted the manuscript. $\mathrm{CH}$ conducted the experiments helped in providing information and preparation of tables and figures. RM-V revised, corrected and commented on the manuscript. RA conceptualised, analyzed the data and edited the

\section{REFERENCES}

Aboelkheir, M. G., Bedor, P. B., Leite, S. G., Pal, K., Toledo Filho, R. D., and Gomes De Souza, F., Jr. (2019). Biodegradation of Vulcanized SBR: A Comparison between Bacillus Subtilis, Pseudomonas aeruginosa and Streptomyces Sp. Scientific Rep. 9, 19304. doi:10.1038/s41598-019-55530-y

Adachi, K., and Tainosho, Y. (2004). Characterization of Heavy Metal Particles Embedded in Tire Dust. Environ. Int. 30, 1009-1017. doi:10.1016/ j.envint.2004.04.004

Alawais, A., and West, R. P. (2019). Ultra-violet and Chemical Treatment of Crumb Rubber Aggregate in a Sustainable concrete Mix. J. Struct. Integrity Maintenance 4, 144-152. doi:10.1080/24705314.2019.1594603

Andler, R. (2020). Bacterial and Enzymatic Degradation of Poly(cis-1,4-Isoprene) Rubber: Novel Biotechnological Applications. Biotechnol. Adv. 44, 107606. doi:10.1016/j.biotechadv.2020.107606

Asaro, L., Gratton, M., Seghar, S., and Ait Hocine, N. (2018). Recycling of Rubber Wastes by Devulcanization. Resour. Conservation Recycling 133, 250-262. doi:10.1016/j.resconrec.2018.02.016

Beard, S., Paradela, A., Albar, J., and Jerez, C. (2011). Growth of Acidithiobacillus Ferrooxidans ATCC 23270 in Thiosulfate under Oxygen-Limiting Conditions Generates Extracellular Sulfur Globules by Means of a Secreted Tetrathionate Hydrolase. Front. Microbiol. 2, 79. doi:10.3389/fmicb.2011.00079

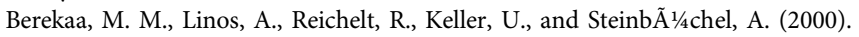
Effect of Pretreatment of Rubber Material on its Biodegradability by Various Rubber Degrading Bacteria. FEMS Microbiol. Lett. 184, 199-206. doi:10.1111/ j.1574-6968.2000.tb09014.x

Bockstal, L., Berchem, T., Schmetz, Q., and Richel, A. (2019). Devulcanisation and Reclaiming of Tires and Rubber by Physical and Chemical Processes: A Review. J. Clean. Prod. 236, 117574. doi:10.1016/j.jclepro.2019.07.049

Bredberg, K., Andersson, B. E., Landfors, E., and Holst, O. (2002). Microbial Detoxification of Waste Rubber Material by wood-rotting Fungi. Bioresour. Technol. 83, 221-224. doi:10.1016/s0960-8524(01)00218-8

Cepeda-Jiménez, C. M., Pastor-Blas, M. M., Ferrándiz-Gómez, T. P., and MartínMartínez, J. M. (2000). Surface Characterization of Vulcanized Rubber Treated with Sulfuric Acid and its Adhesion to Polyurethane Adhesive. J. Adhes. 73, 135-160. doi:10.1080/00218460008029303

Cho, K. S., Ryu, H. W., and Choi, H. M. (2008). Toxicity Evaluation of Complex Metal Mixtures Using Reduced Metal Concentrations: Application to Iron Oxidation by Acidithiobacillus Ferrooxidans. J. Microbiol. Biotechnol. 18, 1298-1307.

Chritiansson, M., Stenberg, B., Wallenberg, L. R., and Holst, O. (1998). Reduction of Surface sulphur upon Microbial Devulcanization of Rubber Materials. Biotechnol. Lett. 20, 637-642. doi:10.1023/a:1005306220566

Colom, X., Faliq, A., Formela, K., and Cañavate, J. (2016). FTIR Spectroscopic and Thermogravimetric Characterization of Ground Tyre Rubber Devulcanized by Microwave Treatment. Polym. Test. 52, 200-208. doi:10.1016/j.polymertesting.2016.04.020 manuscript. All authors read and approved the final manuscript.

\section{FUNDING}

This research was financially supported by FONDECYT Grant 11190220 from ANID (Chile).

\section{SUPPLEMENTARY MATERIAL}

The Supplementary Material for this article can be found online at: https://www.frontiersin.org/articles/10.3389/fenvs.2021.633165/ full\#supplementary-material

de Sousa, F. D. B., Scuracchio, C. H., Hu, G.-H., and Hoppe, S. (2017). Devulcanization of Waste Tire Rubber by Microwaves. Polym. Degrad. Stab. 138, 169-181. doi:10.1016/j.polymdegradstab.2017.03.008

Didier, S., Michel, D., and Christopher, R. (2006). Microwaves in Organic Synthesis. Weinheim: Wiley VCH.

Dobrotă, D., and Dobrotă, G. (2018). An Innovative Method in the Regeneration of Waste Rubber and the Sustainable Development. J. Clean. Prod. 172, 3591-3599. doi:10.1016/j.jclepro.2017.03.022

Dzulkifli, A. I., Said, C. M. S., Han, C. C., and Mohd, A. F. (2016). "Rubber-Solvent Interaction Parameter $(\chi 1,2)$ of NR/SBR Rubber Blend Solution in Determination of Crosslink Concentration for Vulcanized Rubber Blend," in Advanced Materials Research: Trans Tech Publ, 75-81.

Formela, K., Hejna, A., Zedler, L., Colom, X., and Canavate, J. (2019). Microwave Treatment in Waste Rubber Recycling - Recent Advances and Limitations. Express Polym. Lett. 13, 565-588. doi:10.3144/expresspolymlett.2019.48

Ganchev, S. I., Bhattacharyya, J., Bakhtiari, S., Qaddoumi, N., Brandenburg, D., and Zoughi, R. (1994). Microwave Diagnosis of Rubber Compounds. IEEE Trans. Microwave Theor. Techn. 42, 18-24. doi:10.1109/22.265523

Ghosh, W., and Dam, B. (2009). Biochemistry and Molecular Biology of Lithotrophic Sulfur Oxidation by Taxonomically and Ecologically Diverse Bacteria and Archaea. FEMS Microbiol. Rev. 33, 999-1043. doi:10.1111/ j.1574-6976.2009.00187.x

Gorassini, A., Adami, G., Calvini, P., and Giacomello, A. (2016). ATR-FTIR Characterization of Old Pressure Sensitive Adhesive tapes in Historic Papers. J. Cult. Heritage 21, 775-785. doi:10.1016/j.culher.2016.03.005

Grewal, A., Kumar, K., Redhu, S., and Bhardwaj, S. (2013). Microwave Assisted Synthesis: a green Chemistry Approach. Int. Res. J. Pharm. Appl. Sci. 3, 278-285.

Hirose, T., Suzuki, H., Inagaki, K., Tanaka, H., Tano, T., and Sugio, T. (1991). Inhibition of Sulfur Use by Sulfite Ion in Thiobacillus Ferrooxidans. Agric. Biol. Chem. 55, 2479-2484. doi:10.1271/bbb1961.55.2479

Holst, O., Stenberg, B., and Christiansson, M. (1998). Biotechnological Possibilities for Waste Tyre-Rubber Treatment. Biodegradation 9, 301-310. doi:10.1023/a: 1008337708006

Jiang, G., Zhao, S., Luo, J., Wang, Y., Yu, W., and Zhang, C. (2010). Microbial Desulfurization for NR Ground Rubber by Thiobacillus Ferrooxidans. J. Appl. Polym. Sci. 116, 2768-2774. doi:10.1002/app.31904

Kabil, O., and Banerjee, R. (2012). Characterization of Patient Mutations in Human Persulfide Dioxygenase (ETHE1) Involved in H2S Catabolism. J. Biol. Chem. 287, 44561-44567. doi:10.1074/jbc.m112.407411

Kelly, D. P., and Wood, A. P. (2000). Reclassification of Some Species of Thiobacillus to the Newly Designated Genera Acidithiobacillus Gen. nov., Halothiobacillus Gen. Nov. And Thermithiobacillus Gen. Nov. Int. J. Syst. Evol. Microbiol. 50, 511-516. doi:10.1099/00207713-50-2-511

Larsen, M., Schultz, L., Glarborg, P., Skaarupjensen, L., Damjohansen, K., Frandsen, F., et al. (2006). Devolatilization Characteristics of Large Particles of Tyre Rubber under Combustion Conditions. Fuel 85, 1335-1345. doi:10.1016/j.fuel.2005.12.014 
Li, Y., Zhao, S., and Wang, Y. (2012). Microbial Desulfurization of Ground Tire Rubber by Sphingomonas sp.: A Novel Technology for Crumb Rubber Composites. J. Polym. Environ. 20, 372-380. doi:10.1007/s10924-011-0386-1

Li, Y., Zhao, S., and Wang, Y. (2011). Microbial Desulfurization of Ground Tire Rubber by Thiobacillus Ferrooxidans. Polym. Degrad. Stab. 96, 1662-1668. doi:10.1016/j.polymdegradstab.2011.06.011

Liu, H., Wang, X., and Jia, D. (2020). Recycling of Waste Rubber Powder by Mechano-Chemical Modification. J. Clean. Prod. 245, 118716. doi:10.1016/ j.jclepro.2019.118716

Ma, S., Yao, J., Jin, X., Cui, J., and Ma, J. (2011). Progress for thermal and Nonthermal Effects of Microwave Chemistry. Chem. Bull./Huaxue Tongbao 74, 41-46.

Mok, K., and Eng, A. (2018). Characterisation of Crosslinks in Vulcanised Rubbers: From Simple to Advanced Techniques. Malaysian J. Chem. 20, 118-127.

Monadjemi, S., Mcmahan, C. M., McMahan, C., and Cornish, K. (2016). Effect of Non-rubber Constituents on Guayule and Hevea Rubber Intrinsic Properties. J. Res. Updates Polym. Sci. 5, 87-96. doi:10.6000/1929-5995.2016.05.03.1

Moseley, J. D., and Woodman, E. K. (2009). Energy Efficiency of Microwave- and Conventionally Heated Reactors Compared at Meso Scale for Organic Reactions. Energy Fuels 23, 5438-5447. doi:10.1021/ef900598m

Mukherjee, S., and Borthakur, P. C. (2001). Chemical Demineralization/ desulphurization of High sulphur Coal Using Sodium Hydroxide and Acid Solutions. Fuel 80, 2037-2040. doi:10.1016/s0016-2361(01)00094-1

Nawong, C., Umsakul, K., and Sermwittayawong, N. (2018). Rubber Gloves Biodegradation by a Consortium, Mixed Culture and Pure Culture Isolated from Soil Samples. Braz. J. Microbiol. 49, 481-488. doi:10.1016/j.bjm.2017.07.006

Ohshiro, T., Suzuki, K., and Izumi, Y. (1997). Dibenzothiophene (DBT) Degrading Enzyme Responsible for the First Step of DBT Desulfurization by Rhodococcus Erythropolis D-1: Purification and Characterization. J. Ferment. Bioeng. 83, 233-237. doi:10.1016/s0922-338x(97)80985-3

Pinheiro, F. C., Babos, D. V., Barros, A. I., Pereira-Filho, E. R., and Nóbrega, J. A. (2019). Microwave-assisted Digestion Using Dilute Nitric Acid Solution and Investigation of Calibration Strategies for Determination of as, $\mathrm{Cd}, \mathrm{Hg}$ and $\mathrm{Pb}$ in Dietary Supplements Using ICP-MS. J. Pharm. Biomed. Anal. 174, 471-478. doi:10.1016/j.jpba.2019.06.018

Sattler, S. A., Wang, X., Lewis, K. M., Dehan, P. J., Park, C.-M., Xin, Y., et al. (2015). Characterizations of Two Bacterial Persulfide Dioxygenases of the Metalloß-Lactamase Superfamily. J. Biol. Chem. 290, 18914-18923. doi:10.1074/ jbc.m115.652537

Scuracchio, C. H., Waki, D. A., and Da Silva, M. L. C. P. (2007). Thermal Analysis of Ground Tire Rubber Devulcanized by Microwaves. J. Therm. Anal. Calorim. 87, 893-897. doi:10.1007/s10973-005-7419-8

Shakirullah, M., Ahmad, I., Ahmad, W., and Ishaq, M. (2010). Desulphurization Study of Petroleum Products through Extraction with Aqueous Ionic Liquids. J. Chilean Chem. Soc. 55, 179-183. doi:10.4067/s0717-97072010000200007

Shakya, P. R., Shrestha, P., Tamrakar, C. S., and Bhattarai, P. (2006). Studies and Determination of Heavy Metals in Waste Tyres and Their Impacts on the Environment. Pakistan J. Anal. Chem. 7, 70-76.

Sienkiewicz, M., Janik, H., Borzędowska-Labuda, K., and Kucińska-Lipka, J. (2017). Environmentally Friendly Polymer-Rubber Composites Obtained from Waste Tyres: A Review. J. Clean. Prod. 147, 560-571. doi:10.1016/j.jclepro.2017.01.121

Soleimani, M., Bassi, A., and Margaritis, A. (2007). Biodesulfurization of Refractory Organic Sulfur Compounds in Fossil Fuels. Biotechnol. Adv. 25, 570-596. doi:10.1016/j.biotechadv.2007.07.003

Stevenson, K., Stallwood, B., and Hart, A. G. (2008). Tire Rubber Recycling and Bioremediation: A Review. Bioremediation J. 12, 1-11. doi:10.1080/ 10889860701866263
Subramaniam, A. (1987). "Natural Rubber," in Rubber Technology. Editor M. Morton (Boston, MA: Springer US), 179-208. doi:10.1007/978-1-46157823-9_6

Sugio, T., Taha, T. M., and Takeuchi, F. (2009). Ferrous Iron Production Mediated by Tetrathionate Hydrolase in Tetrathionate-, Sulfur-, and IronGrownAcidithiobacillus ferrooxidansATCC 23270 Cells. Biosci. Biotechnol. Biochem. 73, 1381-1386. doi:10.1271/bbb.90036

Sun, B., Du, Z., Cao, H., Du, L., and Yu, W. (2017). Oxidation-grafting Surface Modification of Waste Silicone Rubber Composite Insulator Powder: Characterizations and Properties of EPDM/modified Waste Powder Composites. J. Appl. Polym. Sci. 134, 45438. doi:10.1002/app.45438

Tano, T., Kitaguchi, H., Harada, M., Nagasawa, T., and Sugio, T. (1996). Purification and Some Properties of a Tetrathionate Decomposing Enzyme fromThiobacillus Thiooxidans. Biosci. Biotechnol. Biochem. 60, 224-227. doi: $10.1271 / \mathrm{bbb} .60 .224$

Tao, X., Xu, N., Xie, M., and Tang, L. (2014). Progress of the Technique of Coal Microwave Desulfurization. Int. J. Coal Sci. Technol. 1, 113-128. doi:10.1007/ s40789-014-0006-5

Valdes, J., Pedroso, I., Quatrini, R., Dodson, R. J., Tettelin, H., Blake, R., 2nd, et al. (2008). Acidithiobacillus Ferrooxidans Metabolism: from Genome Sequence to Industrial Applications. BMC Genomics 9, 597. doi:10.1186/1471-2164-9-597

Vishniac, W., and Santer, M. (1957). The Thiobacilli,. Bacteriol. Rev. 21, 195-213. doi:10.1128/br.21.3.195-213.1957

Wang, R., Lin, J.-Q., Liu, X.-M., Pang, X., Zhang, C.-J., Yang, C.-L., et al. (2019). Sulfur Oxidation in the Acidophilic Autotrophic Acidithiobacillus Spp. Front. Microbiol. 9, 3290. doi:10.3389/fmicb.2018.03290

Yang, X., Shen, A., Li, B., Wu, H., Lyu, Z., Wang, H., et al. (2020). Effect of Microwave-Activated Crumb Rubber on Reaction Mechanism, Rheological Properties, thermal Stability, and Released Volatiles of Asphalt Binder. J. Clean. Prod. 248, 119230. doi:10.1016/j.jclepro.2019.119230

Yu, Y., Liu, X., Wang, H., Li, X., and Lin, J. (2014). Construction and Characterization of tetH Overexpression and Knockout Strains of Acidithiobacillus Ferrooxidans. J. Bacteriol. 196, 2255-2264. doi:10.1128/ jb.01472-13

Zhan, Y., Yang, M., Zhang, S., Zhao, D., Duan, J., Wang, W., et al. (2019). Iron and Sulfur Oxidation Pathways of Acidithiobacillus Ferrooxidans. World J. Microbiol. Biotechnol. 35, 60. doi:10.1007/s11274-019-2632-y

Zhang, R., Wei, D., Shen, Y., Liu, W., Lu, T., and Han, C. (2016). Catalytic Effect of Polyethylene Glycol on Sulfur Oxidation in Chalcopyrite Bioleaching by Acidithiobacillus Ferrooxidans. Minerals Eng. 95, 74-78. doi:10.1016/ j.mineng.2016.06.021

Zhong, B., Jia, Z., Hu, D., Luo, Y., Guo, B., and Jia, D. (2016). Surface Modification of Halloysite Nanotubes by Vulcanization Accelerator and Properties of Styrene-Butadiene Rubber Nanocomposites with Modified Halloysite Nanotubes. Appl. Surf. Sci. 366, 193-201. doi:10.1016/j.apsusc.2016.01.084

Conflict of Interest: The authors declare that the research was conducted in the absence of any commercial or financial relationships that could be construed as a potential conflict of interest.

Copyright (c) 2021 Valdés, Hernández, Morales-Vera and Andler. This is an openaccess article distributed under the terms of the Creative Commons Attribution License (CC BY). The use, distribution or reproduction in other forums is permitted, provided the original author(s) and the copyright owner(s) are credited and that the original publication in this journal is cited, in accordance with accepted academic practice. No use, distribution or reproduction is permitted which does not comply with these terms. 